\title{
Galectin-3 activates TLR4/NF-KB signaling to promote lung adenocarcinoma cell proliferation through activating IncRNA- NEAT1 expression
}

Wu Zhou, Xing Chen, Qinghua Hu, Xuliang Chen, Yingji Chen and Lingjin Huang*

\begin{abstract}
Background: Lung cancer remains the top contributor to cancer-related mortality worldwide. Long non-coding RNAs (IncRNAs) have been reported to participate in normal development and tumorigenesis. LncRNA nuclear enriched abundant transcript 1 (NEAT1) is highly expressed in lung cancer and promotes lung cancer cell proliferation and migration. However, the upstream regulatory mechanism still needs investigation.

Methods: In the present study, we investigated the upstream regulators and mechanisms of NEAT1 expression disorders. We first examined NEAT1 expression in lung adenocarcinoma tissues and its correlation with clinic features in patient with lung adenocarcinoma; next, the detailed function of NEAT1 in lung cancer cell proliferation and migration was assessed. To investigate whether NF-KB acts as a transcription factor of NEAT1 to activate its expression, we validated the combination between NF-KB and NEAT1, and NF-KB regulation of NEAT1 upon LPS stimulation. Further, the effect of NF-KB upstream regulator, TLR4, on NEAT1 expression upon LPS stimulation was examined. Galectin-3 reportedly serves as a ligand of TLR4 and promotes TLR4, MyD88 and p-p65 expression; we investigated whether Galectin-3 could modulate lung adenocarcinoma cell proliferation and migration through TLR4/NF-KB/NEAT1. Finally, the expression and correlation of the above factors in lung adenocarcinoma tissues was validated.

Results: NEAT1 is highly expressed in lung adenocarcinoma tissues and promotes lung cancer cell proliferation and migration. NF-KB binds to NEAT1 promoter to activate NEAT1 expression after LPS-stimulated p65 nucleus translocation. LPS stimulation activates TLR4 signaling, followed by downstream NF-kB activation, and ultimately NEAT1 expression activation. Galectin-3 activates TLR4 signaling thus affecting lung cancer cell proliferation and migration through TLR4/NF-KB/NEAT1. Galectin-3 and TLR4 expression are abnormally up-regulated in lung adenocarcinoma tissues, and positively correlated with NEAT1 expression.

Conclusion: We confirmed that Galectin-3 as a ligand of TLR4 induced TLR4 signaling activation in lung adenocarcinoma cells, thereby activating downstream p65 nucleus translocation, promoting NEAT1 expression, and finally affecting lung adenocarcinoma cell proliferation and migration. Inhibiting Galectin-3-induced TLR4 signaling activation, thus to reduce p65-activated NEAT1 expression might be a promising strategy of suppressing lung adenocarcinoma cell proliferation and migration.
\end{abstract}

Keywords: Galectin-3, TLR4, Lung adenocarcinoma, Proliferation, IncRNA-NEAT1

\footnotetext{
*Correspondence: drhuanglj@aliyun.com; drhlj@csu.edu.cn

Department of Cardiothoracic Surgery, Xiangya Hospital, Central-South

University, Xiangya road 87, Changsha 410078, Hunan, China
}

(c) The Author(s). 2018 Open Access This article is distributed under the terms of the Creative Commons Attribution 4.0 International License (http://creativecommons.org/licenses/by/4.0/), which permits unrestricted use, distribution, and reproduction in any medium, provided you give appropriate credit to the original author(s) and the source, provide a link to the Creative Commons license, and indicate if changes were made. The Creative Commons Public Domain Dedication waiver (http://creativecommons.org/publicdomain/zero/1.0/) applies to the data made available in this article, unless otherwise stated. 


\section{Background}

Lung cancer has been regarded as a main cause of cancer incidence and cancer-leading mortality worldwide; less than $20 \%$ patients with lung cancer obtain an overall survival $>5$ years $[1,2]$. Lung adenocarcinoma, rising as the main histological type of lung cancer due to changes in lifestyle such as smoking habit, accounts for approximately up to $50 \%$ of lung cancer cases [3]. Unfortunately, most lung adenocarcinoma patients treated with standard cytotoxic chemotherapy ultimately develop drug-resistance. Developing more effective strategies or targeted agents can be of great clinic value for lung adenocarcinoma treatment.

It is well-known that over $90 \%$ of the human DNA could be transcribed with up to $2 \%$ of them encode protein; this part of transcripts that do not encode protein are called non-coding RNAs (ncRNAs) $[4,5]$. Long noncoding RNAs (lncRNAs) participate in normal developmental and pathological processes, including cancers [6]. For example, lncRNA NEAT1 facilitates pancreatic cancer progression through negatively modulating miR-506$3 p$ [7]. In breast cancer, NEAT1 interacts with miR-101 to modulate cancer cell proliferation through EZH2 [8]. In lung cancer, NEAT1 acts as an oncogenic lncRNA through affecting cancer cell proliferation, invasion and migration via different downstream signaling pathways [9-11]. More importantly, NEAT1 expression is dramatically upregulated in plasma samples of patients with NSCLC (non-small cell lung cancer); higher NEAT1 expression may be related to tumorigenesis and progression of NSCLC, suggesting the application of NEAT1 in personalized targeted therapy $[12,13]$. Investigating the upstream regulators and mechanisms of NEAT1 expression disorders may provide a novel perspective to modulate lung adenocarcinoma cell hyperproliferation and migration.

$\mathrm{NF}-\mathrm{kB}$ is a protein complex which can affect DNA transcription, cytokine release and cell survival [14]; it has been regarded as a key transcription factor which is constitutively activated in many cancers [15-18]; NF-kB activation is a crucial contributor in cancer progression $[19,20]$. Commonly, NF-kB activity is shut down by ІкB binding NF- $\mathrm{KB}$ complex to prevent the nucleus translocation, thus maintaining an inactive state of $\mathrm{NF}-\mathrm{kB}$ [17-19]. Cell stimulation including pro-inflammatory factors TNF- $\alpha$, IL-1 and bacterial lipopolysac-charide (LPS) disrupts this dynamic balance between cytosolic and nuclear localization, leading to NF- $\mathrm{kB}$ nucleus translocation and downstream gene expression which may contribute to cancer cell survival, growth and metastasis [21]. Interestingly, aberrant NF- $\mathrm{kB}$ activation commonly happens in many malignant tumors, including lung cancer $[22,23]$. Whether NF-kB can be aberrantly activated by upstream regulators, thus activating NEAT1 expression in lung adenocarcinoma still remains unclear.
Here, we explored the upstream regulatory factors and mechanisms of NEAT1 abnormal overexpression in lung adenocarcinoma, and further suggest a regulatory path formed by Galectin-3, TLR4, NF-kB and NEAT1 that may contribute to the hyperproliferation and migration of lung adenocarcinoma cells.

\section{Methods}

\section{Tissues and cell lines}

Eighty-three cases of lung adenocarcinoma tissues and matched non-cancerous tissues were collected from patients who accepted surgery at the authors' institution under the approval of Ethic Committee of the institution. These specimens were sent for routine pathological evaluation or instantly frozen in LN (liquid nitrogen).

Two human lung cancer cell lines, A549 (CCL-185 ${ }^{\mathrm{TM}}$ ) and H1299 (CRL-5803 ${ }^{\mathrm{Tn}}$ ) were purchased from ATCC (Manassas, VA, USA) and cultured in RPMI 1640 with $10 \%$ FBS (Gibco ${ }^{\circ}$, Waltham, MA, USA). For LPS and CLI-095 treatment, 20 ng/ml LPS (Sigma, St. Louis, MI, USA) or $50 \mathrm{nmol} / \mathrm{L}$ CLI-095 (Invitrogen, Waltham, MA, USA) was used to stimulate the target cells for $4 \mathrm{~h}$, then cells were harvested for further experiments.

\section{Cell transfection}

The suppression of NEAT1 and p65 expression was achieved by transfection of si-NEAT1 or si-p65 (Genepharma, Shanghai, China) with Lipofectamine 2000 agent (Invitrogen). A pcDNA3.1/p65 was used to overexpress p65 expression. Transfection of pcDNA3.1/ Galectin-3 or pLVX/sh-Galectin-3 was performed to overexpressing or knocking down Galectin-3 (GeneCopoecia, Guangzhou, China).

\section{Real-time PCR}

Total RNA was collected from targeted tissues or cells with the help of Trizol reagent (Invitrogen) followed by subsequent DNase I (Invitrogen) treatment following the protocols. cDNA was synthesized with the help of oligo (dT) 20 and Superscript II reverse transcriptase (Invitrogen). The expression of mRNA was examined using SYBR green PCR Master Mix (Qiagen, Venlo, Netherlands). The expression of miRNA was examined by a Hairpin-it TM miRNAs qPCR kit (Genepharma). The data were normalized to GAPDH (for mRNA expression) and RNU6B (for miRNA expression), respectively, and analyzed using a $2^{-\Delta \Delta C T}$ method.

\section{Cell viability determination by MTT}

Cell viability was detected using MTT (3-(4,5-dimethylthiazol-2-yl)-2,5-diphenyltetrazolium bromide) assays. The target cells were seeded in 96-well plates in a density of $5 \times 10^{3}$ cells/well; 24 h later, target cells were subjected to transfection of shGal-3 or Gal-3 or si-NEAT1. Fortyeight hours later, the cells were co-incubated with $20 \mu \mathrm{l}$ 
MTT (5 mg/ml; Sigma-Aldrich) in a humidified incubator for $4 \mathrm{~h}$. Thereafter, $200 \mu \mathrm{l}$ DMSO was used to dissolve the formazan after discarding the supernatant. The cell viability was then detected by reading the OD490 $\mathrm{nm}$ value normalizing to non-treated cells.

\section{DNA synthesis capacity by BrdU}

The DNA synthesis capacity was detected by measurement of BrdU incorporation. A549 and H1299 cells $\left(2 \times 10^{3}\right.$ cells/ well) were seeded in 96-well plates and transfected and/or treated as described; twenty-four or forty-eight hours later, BrdU assays were performed. At the end of culturing, $10 \mu \mathrm{M}$ BrdU (BD Pharmingen, San Diego, CA, USA) was added and the target cells were incubated for another two to twenty-four hours, when the medium was discarded and the cells were fixed by RT for $30 \mathrm{~min}$. Then, peroxidase-coupled BrdU antibody (Sigma-Aldrich) was added and the target cells were incubated for $60 \mathrm{~min}$. After washing by PBS and incubation with peroxidase substrate, the OD $450 \mathrm{~nm}$ value was examined. The value of non-exposed cells (incubated with BrdU antibody) was taken as background value.

\section{Migration capacity determination by Transwell assays}

A total of $5 \times 10^{5}$ target cells were transfected and/or treated as described, and seeded onto the upper chamber of polycarbonate Transwell filters (Cell Biolabs, Inc. Santiago, CA, USA) with no Matrigel nor serum at $37{ }^{\circ} \mathrm{C}$ for $48 \mathrm{~h}$; medium with $\mathrm{FBS}$ was used in the bottom chamber. The non-migratory cells on the upper side were cleared away and the migratory cells on the lower side were counted under a microscope after fixing and staining with DAPI (Beyotime Institute of Biotechnology, Haimen, China).

\section{Immunoblotting (western blot, WB)}

The protein levels of Galectin-3, TLR-4, MyD88, p-p65 and p65were examined by immunoblotting. The proteins were extracted from target cell lysate and analyzed for protein concentration using the bicinchoninic acid (BCA) protein assay kit (Beyotime Institute of Biotechnology). Extracted proteins were then loaded onto an SDS-PAGE minigel for separating. Separated proteins were then transferred onto PVDF membrane. Thereafter, the membrane was probed with the antibodies listed below, which were all obtained from Abcam (Cambridge, MA, USA) unless otherwise stated: Galectin-3 (mouse monoclonal, ab2785), TLR-4 (rabbit polyclonal, ab47093), MyD88 (rabbit polyclonal, ab2064), p-p65 (rabbit polyclonal, ab86299) and GAPDH (mouse monoclonal, ab8245) at $4{ }^{\circ} \mathrm{C}$ overnight. Thereafter, the blots were incubated with HRP-conjugated secondary antibody (1:5000). Signals visualization was conducted by ECL Substrates (Millipore, MA, USA) normalizing to GAPDH. The gray intensity analysis was performed using ImageJ software $(\mathrm{NIH})$.

\section{Chromatin immunoprecipitation (ChIP)}

After treating with LPS $(20 \mathrm{ng} / \mathrm{ml})$ for four hours, ChIP assay was performed according to previously described method [24] using anti-p65 (anti-p65, ab16502). The fold-enrichment (FE) of antibody binding DNA was calculated as described [24].

\section{P65-NEAT1 binding validation using luciferase activity}

Two kinds of NEAT1 promoter luciferase reporter vectors were constructed: a wild-type containing wild-type NEAT1 promoter with predicted p65 responsive element (p65 RE), and a mutant-type containing a mutation in both or any of the putative binding sites in p65RE. HEK293 cell was used as a cellular tool to examined the alterations of luciferase activity $48 \mathrm{~h}$ after transfection of reporter vectors in the presence or absence of LPS, respectively using Dual Luciferase Reporter Assay System (Promega, Fitchburg, WI, USA).

\section{HE staining and immunohistochemistry}

Lung adenocarcinoma tissues and the matched adjacent normal tissues were fixed in 10\% formalin overnight and then processed by paraffin embedding and sectioning. Sections with a thickness of $5 \mu \mathrm{m}$ were deparaffinized and rehydrated. Sections were then stained using HE staining kit (Beyotime, China) following the protocols. Immunohistochemical staining for Galectin-3 and TLR4 in lung adenocarcinoma tissues was performed as described previously [25] using Galectin-3 (ab2785) or TLR4 (ab47093) antibodies. The HE and immunohistochemical sections were then observed under an optical microscope (Olympus, Tokyo, Japan).

\section{Statistical analysis}

Each experiment was repeated at least three times. Data were processed by SPSS 17.0 (SPSS, Chicago, IL, USA) and exhibited as mean \pm standard deviation (SD). Differences between paired samples were compared using the Student's paired test. The differences of more than two groups were evaluated using the one-way ANOVA. Kaplan-Meier analysis and the log-rank test were used to analyze the overall survival curves in patients with lung cancer. COX risk proportional regression model (univariate analysis and multivariate analysis) was employed to identify the risk factors for survival in patients with lung cancer. $P$ values of $<0.05$ were considered statistically significant. 


\section{Results}

NEAT1 expression in lung adenocarcinoma tissue samples and its correlation with overall survival

NEAT1 is abnormally expressed in lung cancer and acts as an oncogene $[9,10,13]$; herein, we first validated NEAT1 expression in 83 paired lung adenocarcinoma and adjacent normal specimens, as well as its correlation with the overall survival in patients with lung adenocarcinoma. As shown by real-time PCR, NEAT1 expression was dramatically increased in cancer tissue specimens compared to normal control (Fig. 1a); further analysis indicated that higher NEAT1 expression was more commonly observed in specimens in advanced TNM stages (Fig. 1b) and with lymph node metastasis (Fig. 1c). Patients were grouped as follows: a high NEAT1 group possessing NEAT1 expression higher than the median level and a low NEAT1 group possessing NEAT1 expression lower than the median level; the overall survival of patients in high NEAT1 group was remarkably shorter than that in the low NEAT1 group (Fig. $1 \mathrm{~d}, P=0.016$ ). Moreover, higher NEAT1 expression was correlated with advanced TNM stages $(P=0.031$, Table 1$)$. The association between overall survival and pathological characteristics was analyzed then using a COX risk proportional regression model. Univariate analysis revealed that the difference in overall survival caused by tumor size, TNM stage or NEAT1 expression was statistically significant; multivariate analysis revealed that NEAT1 expression (Table 2) and TNM stages both represented independent factors related to the overall survival of patients involved (Table 2). The data reveal that NEAT1 expression is dysregulated in lung adenocarcinoma; its high expression is associated with shorter overall survival of patients with lung adenocarcinoma.

\section{NEAT1 knockdown inhibits lung cancer cell proliferation and migration}

In order to evaluate the detailed function of NEAT1 in cancer development, NEAT1 knockdown was conducted by transfecting si-NEAT1 into A549 and H1299 cells, as confirmed by real-time PCR (Fig. 2a). Next, the cell viability and DNA synthesis capacity of non-transfected or transfected tumor cells were measured by MTT and BrdU. After NEAT1 knockdown, the cell viability and DNA synthesis capacity of A549 and H1299 was significantly suppressed (Fig. 2b-c), indicating that NEAT1 knockdown could inhibit lung cancer cell proliferation. Moreover, NEAT1 knockdown also suppressed the migration capability of lung cancer cell (Fig. 2d). Consistent with previous studies, NEAT1 may contribute to lung cancer
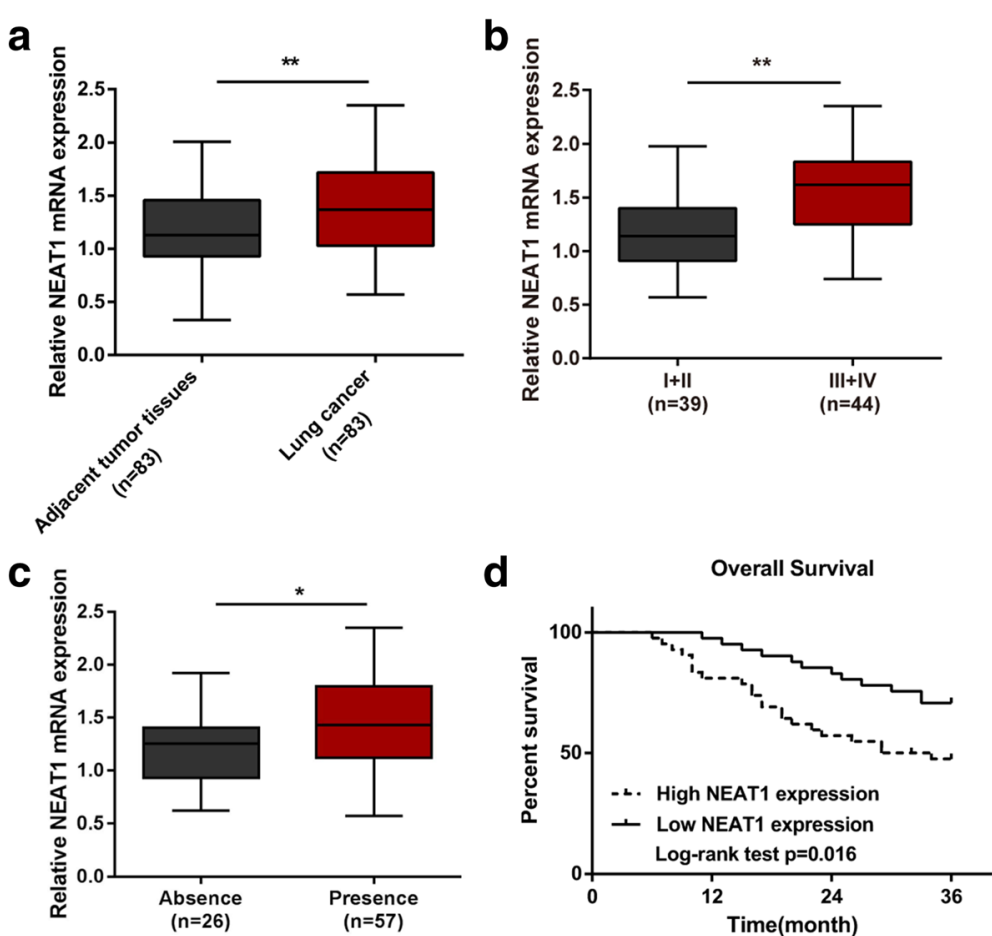

Fig. 1 The role of NEAT1 in the regulation of lung cancer cell proliferation (a) The expression level of NEAT1 in 83 paired lung adenocarcinoma tissues and adjacent normal tissues was determined using real-time PCR assays. b-c NEAT1 expression in 83 cases of lung adenocarcinoma tissues was analyzed according to TNM staging and lymph node metastasis. The data are presented as mean \pm SD of three independent experiments. ${ }^{*} P<0.05,{ }^{*} P<0.01$. (d) Kaplan-Meier overall survival curves for 83 patients with lung adenocarcinoma classified according to relative NEAT1 expression level 
Table 1 Correlation between IncRNA NEAT1 expression and clinicopathological features in lung cancer patients

\begin{tabular}{|c|c|c|c|c|}
\hline \multirow[t]{2}{*}{ Characteristics } & & \multicolumn{2}{|c|}{ NEAT1 expression } & \multirow[t]{2}{*}{$p$-value } \\
\hline & & $\mathrm{HIGH}$ & LOW & \\
\hline \multirow[t]{2}{*}{ Age (years) } & $<50$ & 27 & 21 & 0.228 \\
\hline & $\geq 50$ & 15 & 20 & \\
\hline \multirow[t]{2}{*}{ Gender } & female & 13 & 15 & 0.587 \\
\hline & male & 29 & 26 & \\
\hline \multirow[t]{2}{*}{ Tumor size (cm) } & $<5$ & 22 & 29 & 0.086 \\
\hline & $\geq 5$ & 20 & 12 & \\
\hline \multirow[t]{2}{*}{ Histology } & Adenoma & 23 & 18 & 0.322 \\
\hline & Squamous & 19 & 23 & \\
\hline \multirow[t]{2}{*}{ Differentiation } & Moderate-Poor & 28 & 20 & 0.099 \\
\hline & Well & 14 & 21 & \\
\hline \multirow[t]{4}{*}{ TNM stage } & 1 & 5 & 9 & 0.031 \\
\hline & $\|$ & 8 & 17 & \\
\hline & III & 18 & 10 & \\
\hline & IV & 11 & 5 & \\
\hline \multirow[t]{2}{*}{ Lymph node metastasis } & Absence & 10 & 16 & 0.135 \\
\hline & Presence & 32 & 25 & \\
\hline
\end{tabular}

cell proliferation and migration; thus, inhibiting aberrant NEAT1 overexpression in lung cancer represents a promising strategy for regulating cancer cell growth.

\section{NF-kB binds to NEAT1 promoter region after LPS-stimulated p65 nucleus translocation}

The activation of NF- $\mathrm{kB}$, a key transcription factor which is constitutively activated in many cancers, is a crucial contributor in cancer progression $[19,20]$. NF- $\mathrm{kB}$ can activate the expression of proliferation-, apoptosis- and/or migration-related genes $[14,16,26]$ after multi factor- stimulated p65 nucleus translocation, including TNF- $\alpha$, IL-1 and LPS [21]. Herein, we investigated whether LPS stimulates p65 nucleus translocation and subsequent NEAT1 expression activation. First, we validated the predicted binding between NF- $\kappa$ B and NEAT1 promoter region using luciferase reporter gene assays. Jaspar [27] database predicted that there might be two p65RE in NEAT1 promoter (p65RE, Fig. 3a). Two different types of luciferase reporter vectors, a wild-type NEAT1 (named wt-NEAT1, possessing no mutation) and a mutant-type NEAT1 (named mut-NEAT1, containing any or both of the mutated binding sites) were constructed (Fig. 3a). The vectors were transfected into HEK293 cells in the presence of PBS or LPS, which has been reported to stimulate p65 nucleus translocation. Afterwards, the luciferase activity was examined. LPS treatment significantly amplified the luciferase activity of wt-NKILA, comparing to PBS treatment. When any or both of the two putative binding sites were mutated, LPS-induced luciferase activity alterations were eliminated (Fig. 3b). Moreover, as shown by ChIP assay, the levels of p65 antibody binding to any of the predicted sites in NEAT1 promoter region were higher than those binding to IgG (Fig. 3c-d), suggesting that p65 may bind to the predicted binding site 1 or site 2 within NEAT1 promoter to activate its expression.

Further, A549 and H1299 cells were transfected with si-p65 or p65 vector in the presence of PBS or LPS stimulation; the protein levels of p65 and p65, as well as the mRNA expression of NEAT1 were determined. LPS stimulation caused no obvious changes in p65 protein levels in si-NC (negative control for si-p65) or empty vector (negative control for p65 vector) transfected cancer cells; however, the protein levels of p-p65 were strongly induced by LPS stimulation (Fig. 3e). P65 and p-p65 proteins were reduced by si-p65 while increased

Table 2 Univariate and multivariate analysis for factors related to overall survival using the Cox proportional hazard model

\begin{tabular}{|c|c|c|c|c|c|c|c|}
\hline \multirow[t]{2}{*}{ Characteristics } & & \multicolumn{3}{|c|}{ Univariate analysis } & \multicolumn{3}{|c|}{ Multivariate analysis } \\
\hline & & $\mathrm{p}$ & $\mathrm{HR}$ & $95 \% \mathrm{Cl}$ & $p$ & $H R$ & $95 \% \mathrm{Cl}$ \\
\hline Age & $<50$ vs $\geq 50$ & 0.408 & 1.346 & $0.666-2.721$ & N.A & & \\
\hline Gender & female vs male & 0.685 & 0.862 & $0.420-1.769$ & N.A & & \\
\hline Tumor size & $<5$ vs $\geq 5$ & 0.012 & 0.420 & $0.214-0.825$ & 0.198 & 0.597 & $0.272-1.310$ \\
\hline Histology & Adenoma vs Squamous & 0.603 & 0.836 & $0.426-1.640$ & N.A & & \\
\hline Differentiation & Moderate-Poor vs Well & 0.512 & 1.265 & $0.626-2.558$ & N.A & & \\
\hline \multirow[t]{5}{*}{ TNM stage } & & $<0.001$ & & & 0.002 & & \\
\hline & 1 & 0.008 & 0.242 & $0.085-0.692$ & 0.161 & 0.416 & $0.122-1.417$ \\
\hline & $\|$ & $<0.001$ & 0.094 & $0.030-0.293$ & $<0.001$ & 0.123 & $0.038-0.399$ \\
\hline & III & 0.002 & 0.294 & $0.133-0.649$ & 0.003 & 0.290 & $0.127-0.664$ \\
\hline & IV & & & & & & \\
\hline Lymph node metastasis & Absence vs Presence & 0.426 & 1.363 & $0.636-2.920$ & N.A & & \\
\hline NEAT1 & high vs low & 0.018 & 2.339 & $1.156-4.733$ & 0.035 & 2.199 & $1.055-4.581$ \\
\hline
\end{tabular}




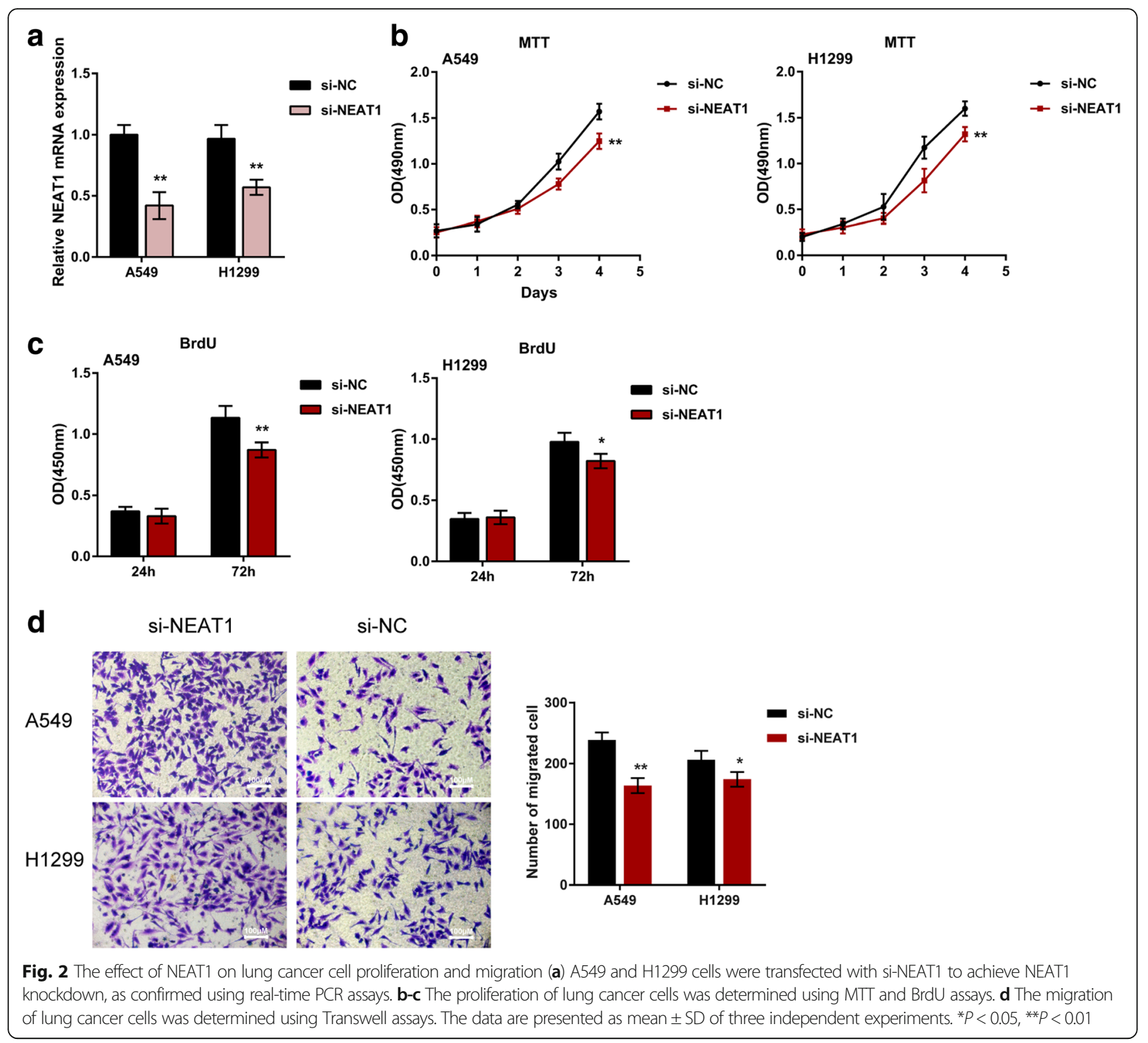

by p65 vector transfection; the inducible effect of LPS on p-p65 protein could be partially reversed by si-p65 while even amplified by p65 vector transfection (Fig. 3e). In addition, LPS stimulation remarkably up-regulated NEAT1 expression; si-p65 transfection partially attenuated, while p65 vector transfection even amplified the promotive effect of LPS on NEAT1 expression as shown by real-time PCR (Fig. 3f). The data suggest that LPS promotes $\mathrm{p} 65$ nucleus translocation, followed by activation of NEAT1 expression in lung cancer cells.

\section{TLR4 signaling is involved in NF-KB-mediated NEAT1 expression activation}

In addition to inducing p65 nucleus translocation, LPS has also been reported to activate TLR4 signaling, which is also an essential pathway in the pathopoiesis of tumors
[28]; interestingly, TLR4/NF- $\mathrm{kB}$ signaling mediates diverse tumor growth [29, 30]. Herein, we investigated whether TLR4 is another component of the upstream regulatory signaling of NEAT1 expression in lung cancer cell lines. A549 and H1299 cells were treated with LPS, known to activate TLR4 signaling, and/or $50 \mathrm{nmol} / \mathrm{L}$ CLI-095, an inhibitor or TLR4 signaling; TLR4, MyD88 and p-p65 protein expression and NEAT1 mRNA expression. In LPS group, the protein levels of TLR4, MyD88 and p-p65 and NEAT1 mRNA expression were all up-regulated (Fig. 4a-c); on the contrary, CLI-095 caused an obvious suppression of TLR4, MyD88 and p-p65 protein expression and NEAT1 mRNA expression (Fig. 4a-c). The data indicated that LPS stimulation activates TLR4 signaling, followed by downstream NF- $\mathrm{kB}$ activation, and ultimately NEAT1 expression activation. 

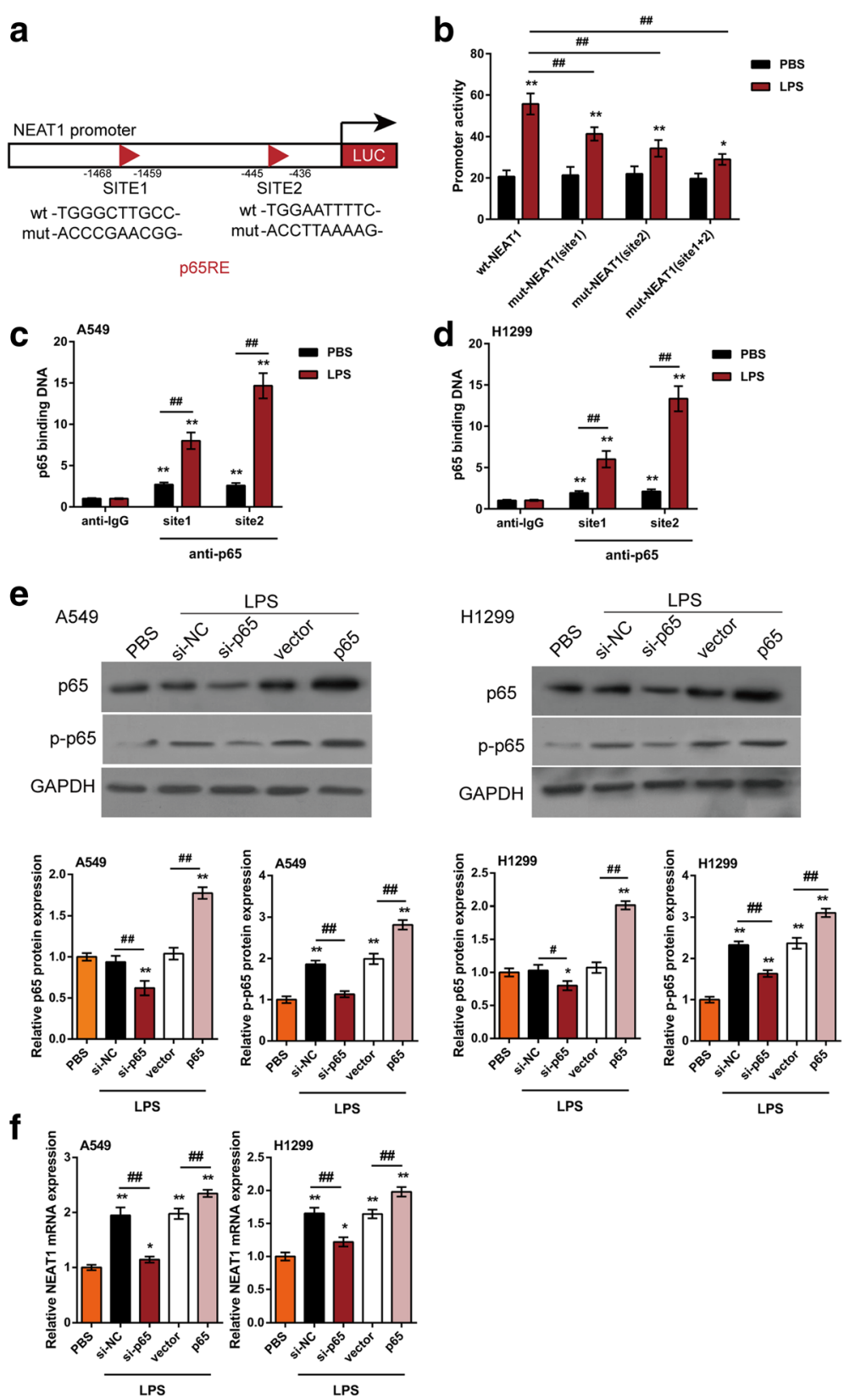

Fig. 3 NF-kB binds to the promoter region of NEAT1 after LPS-stimulated p65 nucleus translocation (a) A schematic diagram of potential p65 binding element (two possible binding sites) in the promoter region of NEAT1 predicted by Jaspar database. A wt-NEAT1 promoter luciferase reporter vector and a mut-NEAT1 promoter luciferase reporter vector were constructed by mutating any or both of the predicted binding sites. $\mathbf{b}$ The indicated vectors were transfected into HEK293 cells and then treated with PBS or LPS (20 ng/ml for 4 h); the luciferase activity was determined. c-d The real-time ChIP assay showed that the level of p65 antibody binding to NEAT1 promoter was much greater than that of lgG. e A549 and H1299 cells were transfected with si-p65 or p65 vector; the protein levels of p65 and p-p65 were determined using Immunoblotting in the presence or absence of LPS (20 ng/ml for 4 h). $\mathbf{f}$ The mRNA expression of NEAT1 was determined using real-time PCR assays. The data are presented as mean \pm SD of three independent experiments. ${ }^{*} P<0.05$, ${ }^{* *} P<0.01$, compared to PBS group; $\# P<0.05$, \#\#P<0.01, compared to si-NC or vector group

\section{Galectin-3 induced TLR4 signaling activation in lung cancer cells}

As we have demonstrated, TLR4/NF-kB/NEAT1 can be activated by LPS stimulation; are there any other dysregulated factors in lung cancer that can modulate this TLR4/NF-kB/NEAT1 axis? Galectin-3 has been regarded as a sensor-regulator in TLR pathways in synovial fibroblasts [31]; moreover, it has been regarded as a ligand of TLR4 and could promote TLR4, MyD88 and p-p65 expression [32, 33]. The overexpression of Galectin-3 has been observed in lung cancer $[34,35]$. Herein, we hypothesized that Galectin-3 may activate TLR4/NF-kB/ 

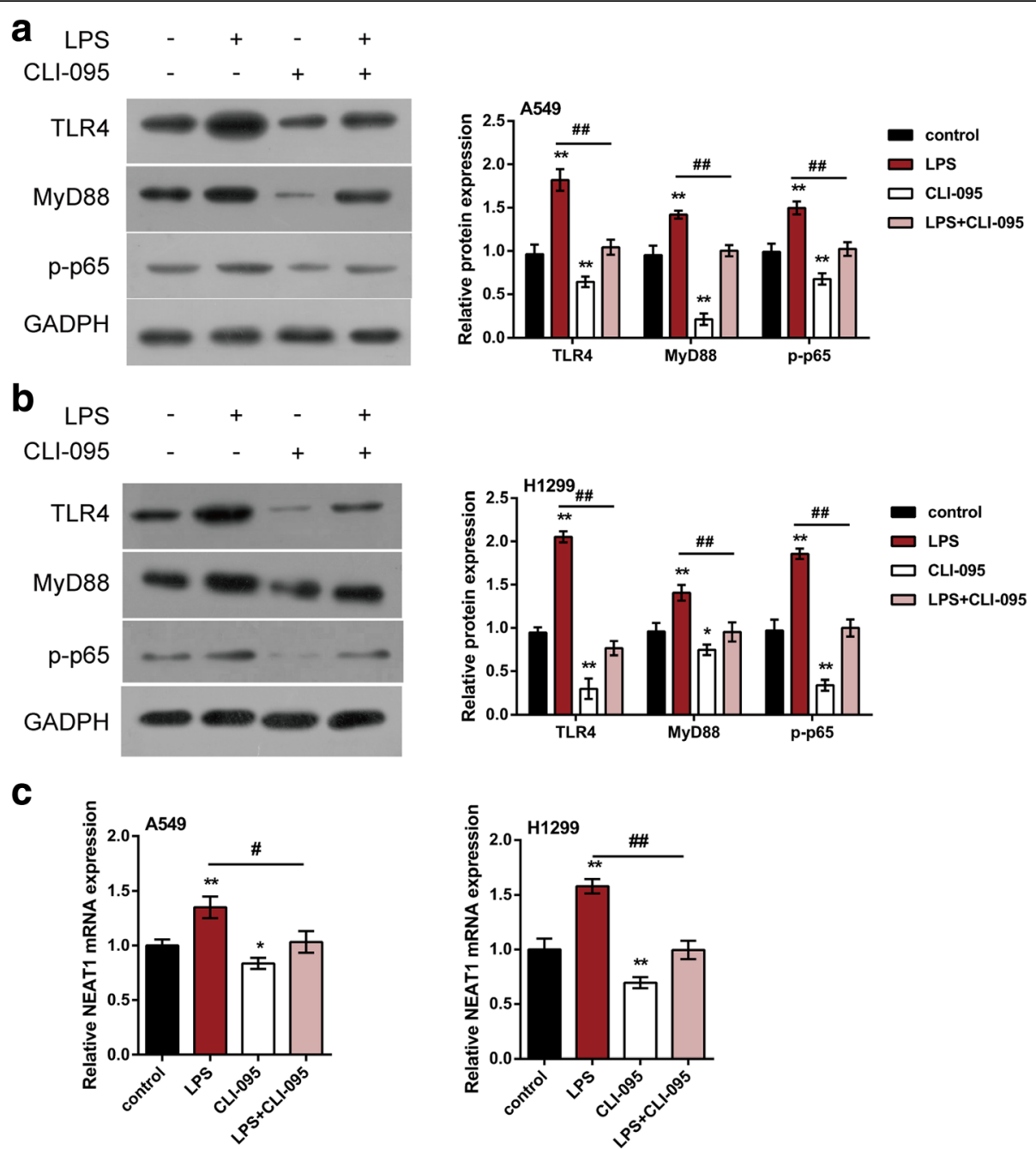

Fig. 4 TLR4 signaling is involved in NF-KB-mediated NEAT1 expression activation (a-b) A549 and H1299 cells were co-treated with LPS (20 ng/ml) and CLI-095 (50 nmol/L) for 4 h; the protein levels of TLR4, MyD88 and p-p65 were determined using Immunoblotting assays. c The mRNA expression of NEAT1 was determined using real-time PCR assays. The data are presented as mean \pm SD of three independent experiments. ${ }^{*} P<0.05,{ }^{*} P<0.01$, compared to control group; $\# P<0.05$, \#\#P<0.01, LPS group compared to LPS + CLI-095 group

NEAT1, thereby affecting lung cancer cell proliferation and migration. To validate this hypothesis, A549 and H1299 cells were transfected with shGal-3 or Gal-3 vector to achieve Galectin-3 knockdown or overexpression, as confirmed by WB (Fig. 5a); TLR4 protein was positively regulated by Galectin-3 (Fig. 5a). Moreover, the cell proliferation and migration of lung cancer cell were significantly suppressed by Galectin-3 knockdown while promoted by Galectin-3 overexpression (Fig. 5b-d), indicating the potential role of Galectin-3 in activating TLR4 signaling and promoting lung cancer progression.

\section{Galectin-3 affects the proliferation and migration of lung} cancer cell lines through TLR4/NF-KB/NEAT1

Given that Galactin-3 positively regulates TLR4 protein expression, as well as the proliferation and migration of lung cancer cell lines; next, we investigated whether Galectin-3 acts through TLR4/NF-kB/NEAT1. A549 and H1299 cells were transfected with Gal-3 in the absence or presence of $50 \mathrm{nmol} / \mathrm{L}$ CLI-095; the protein levels of TLR4, MyD88 and p-p65, and NEAT1 mRNA expression were determined. The results showed that CLI-095 dramatically decreased the protein levels of TLR4, MyD88 and p-p65, and NEAT1 mRNA expression; on the contrary, Gal-3 transfection increased TLR4, MyD88 and p-p65 proteins and NEAT1 mRNA expression; moreover, the inhibitory effect of CLI-095 on the above factors could be partially abolished by Gal-3 transfection (Fig. 6a-b).

Furthermore, we also monitored the changes of lung cancer cell proliferation and migration under the same conditions. Consistent with above results, Galectin-3 

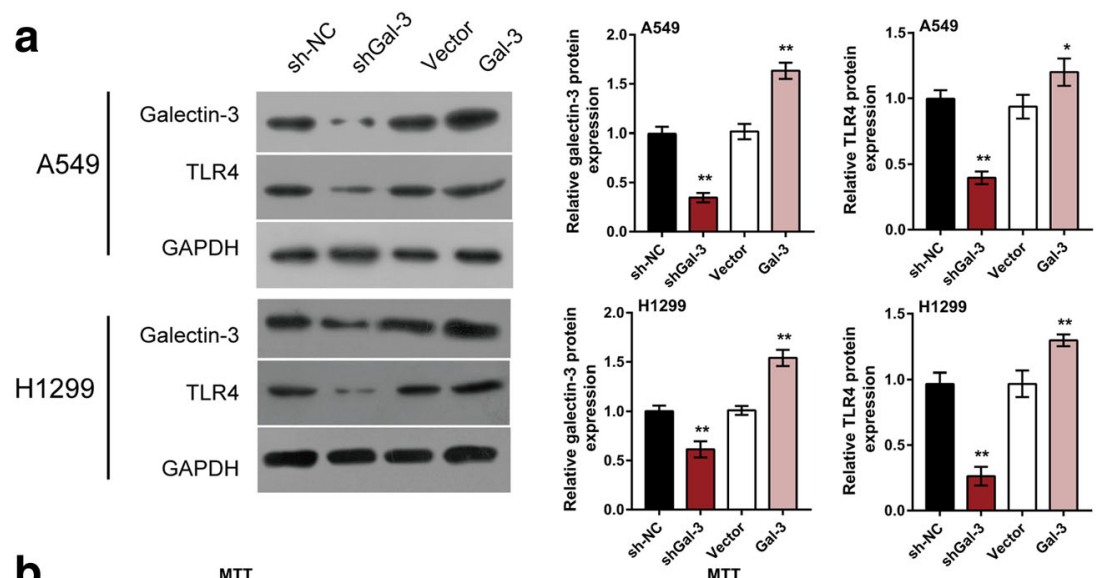

b
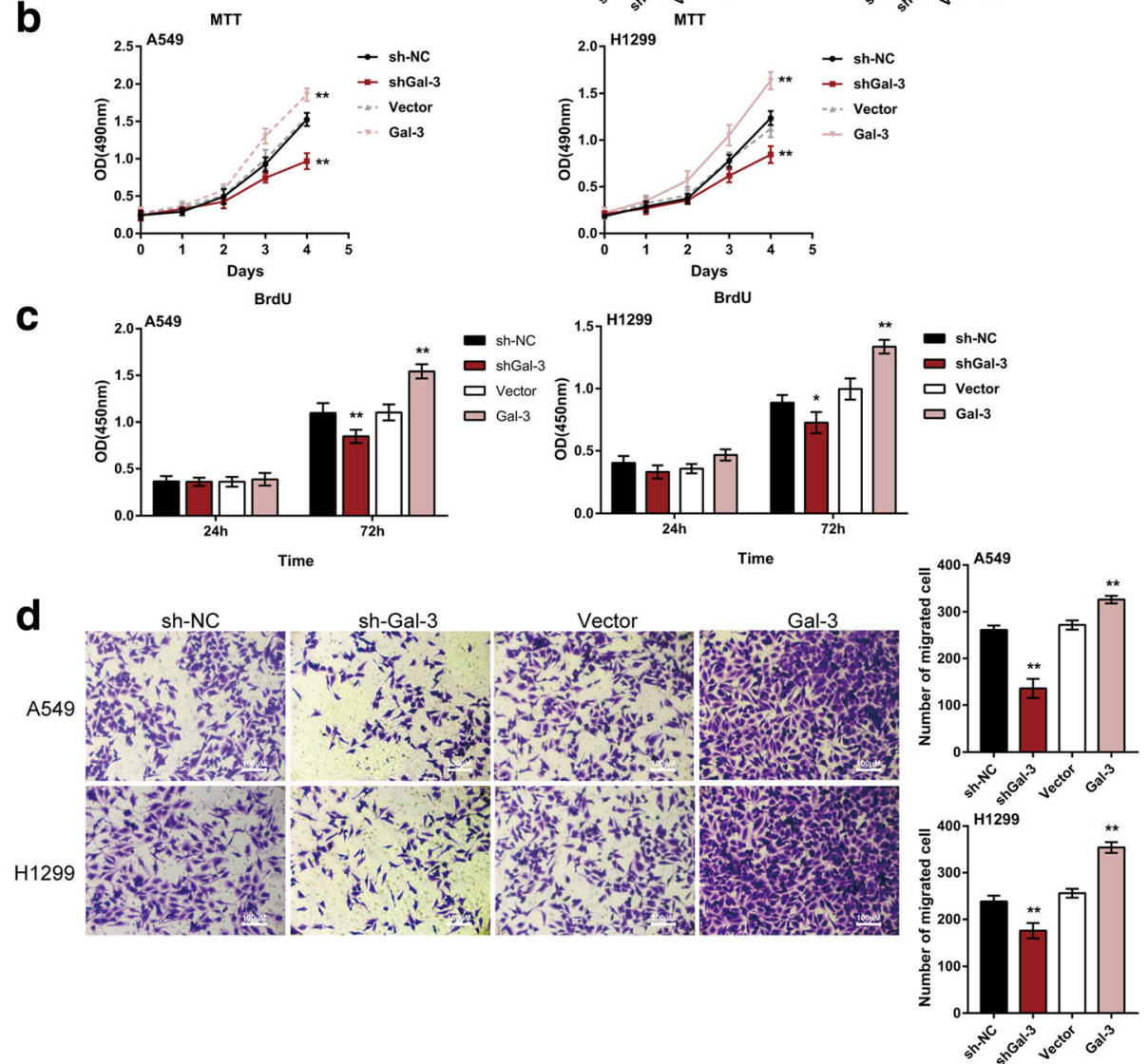

Fig. 5 Galectin-3 induced TLR4 signaling activation in lung cancer cells (a) A549 and H1299 cells were transfected with shGal-3 or Gal-3 vector; the protein levels of Galectin-3 and TLR4 were determined using Immunoblotting assays. b-c The proliferation of lung cancer cell was determined using MTT and BrdU assays. $\mathbf{d}$ The migration of lung cancer cell was determined using Transwell assays. The data are presented as mean \pm SD of three independent experiments. ${ }^{*} P<0.05,{ }^{* *} P<0.01$, compared to sh-NC or Vector group

overexpression significantly promoted, whereas CLI-095 remarkably suppressed the cell proliferation and migration of lung cancer cell lines; the above effects of Galectin-3 were partially eliminated by CLI-095 (Fig. 6c-e), indicating that Galectin-3 activates TLR4 signaling, followed by downstream NF-kB activation and NEAT1 expression upregulation, finally resulting in excessive proliferation and migration of tumor cells.
The expression levels of Galectin-3 and TLR4 in lung adenocarcinoma tissue samples and their correlation with NEAT1

As a further confirmation of these data, the mRNA expression of Galectin-3 and TLR4 in lung adenocarcinoma and non-cancerous tissue samples were examined. As shown by $\mathrm{H} \& \mathrm{E}$ staining, in lung adenocarcinoma tissues, the cancer cells were irregularly arranged and the nucleus shapes of 

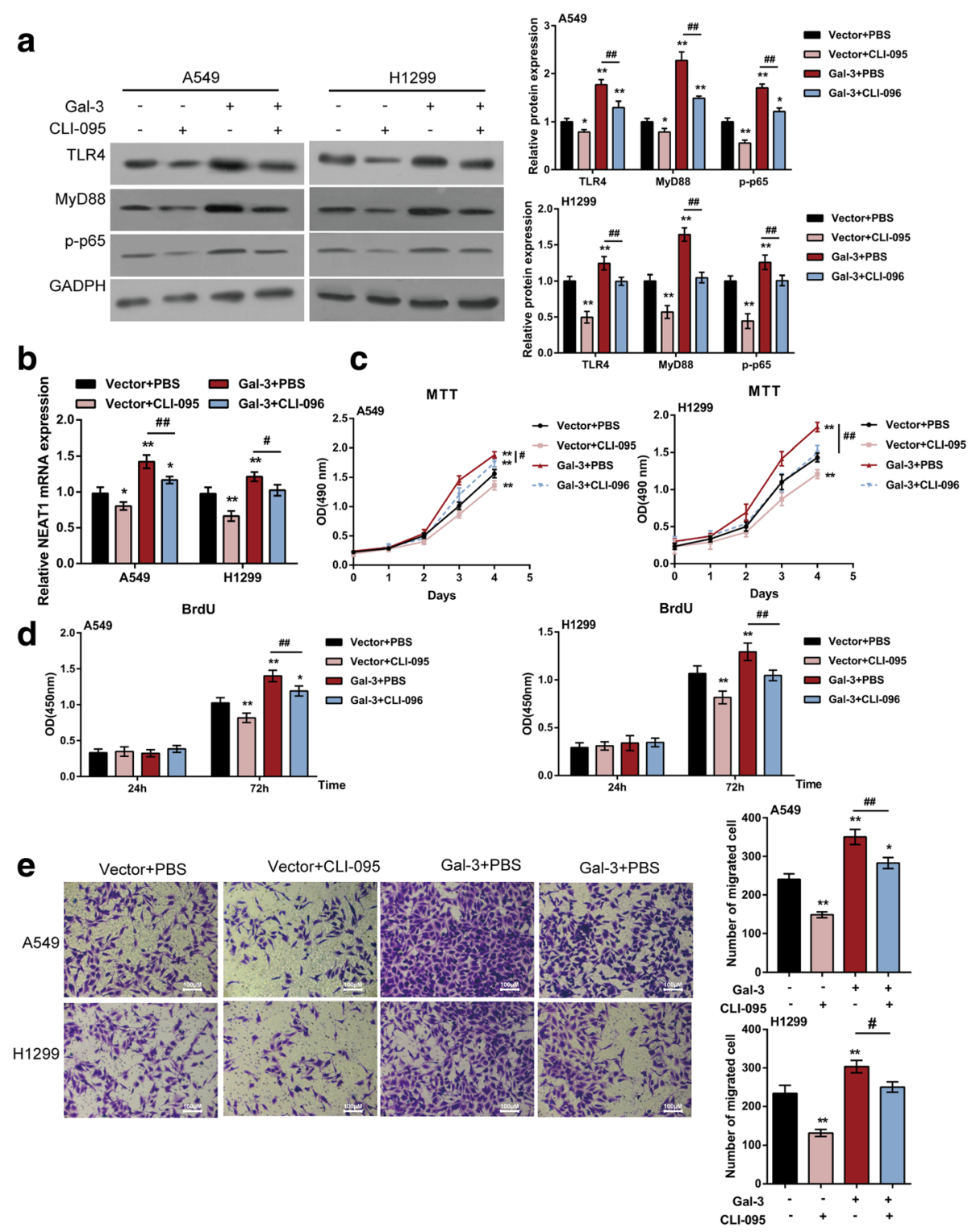

Fig. 6 Galectin-3 affects lung cancer cell proliferation and migration through TLR4/NF-KB/NEAT1 (a) A549 and H1299 cells were transfected with Gal-3 in the presence or absence of CLI-095(50 nmol/L for 4 h); the protein levels of TLR4, MyD88 and p-p65 were determined using Immunoblotting assays. b The mRNA expression of NEAT1 was determined using real-time PCR assays. c-d The proliferation of lung cancer cell was determined using MTT and BrdU assays. e The migration of lung cancer cell was determined using Transwell assays. The data are presented as mean \pm SD of three independent experiments. ${ }^{*} P<0.05,{ }^{*} P<0.01$, compared to control group; $\# P<0.05$, \#\#P<0.01, Gal-3 group compared to Gal-3 + CLI-095 group

the nucleus were shown (Fig. 7a). Galectin-3 and TLR4 were both overexpressed in lung adenocarcinoma tissues, compared to those in non-tumor control (Fig. 7a). Moreover, the mRNA expression and protein levels of Galectin-3 and TLR4 in lung adenocarcinoma samples were much higher than those in normal lung tissues (Fig. 7b-d). Moreover, a positive correlation between Galectin-3 and TLR4 mRNA, between Galectin-3 and NEAT1, between TLR4 and NEAT1 was observed (Fig. 7e-g). The data indicate that Galectin-3 and TLR4 expression are abnormally upregulated in lung adenocarcinoma tissues; Galectin-3 affects lung adenocarcinoma cell proliferation and migration through activating TLR4/NF- $\mathrm{kB}$ pathway and NEAT1 expression.

\section{Discussion}

In the present study, we reported abnormal lncRNANEAT1 overexpression in lung adenocarcinoma specimens; NEAT1 knockdown could inhibit lung cancer cell proliferation and migration. Furthermore, we demonstrated the upstream regulatory mechanism of NEAT1 disorder in lung adenocarcinoma, that is, Galectin-3 


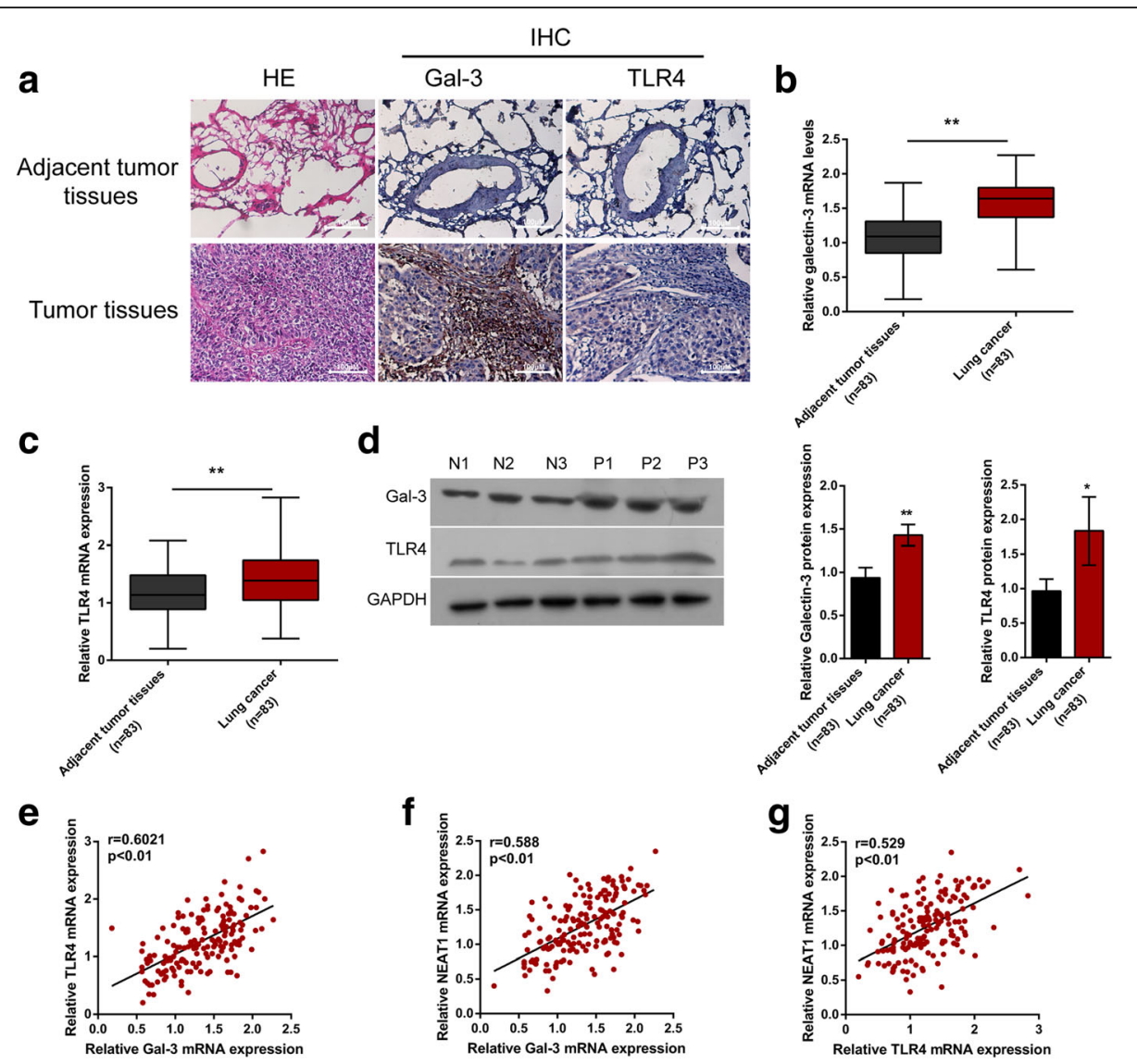

Fig. 7 The expression levels of Galectin-3 and TLR4 in lung adenocarcinoma tissues and their correlation with NEAT1 (a) Pathological morphologic changes of lung adenocarcinoma tissues and adjacent normal tissues were shown by H\&E staining; Gal-3 and TLR4 expression in lung adenocarcinoma tissues and adjacent normal tissues were shown by $\mathrm{HC}$ staining. b-d The mRNA and protein expression of Galectin-3 and TLR4 in lung adenocarcinoma tissues and adjacent normal tissues was determined using real-time PCR and Immunoblotting assays. The data are presented as mean \pm SD of three independent experiments. ${ }^{*} P<0.05$, ${ }^{* *} P<0.01$. e-g The correlation of Galectin-3, TLR4 and NEAT1 was analyzed using Spearman's rank correlation analysis

activates TLR4/NF-кB signaling, followed by p65 nucleus translocation, ultimately activating NEAT1 expression and promoting lung adenocarcinoma cell proliferation and migration (Fig. 8).

The essential role of IncRNA in cancers has been frequently reported. Dysfunction of lncRNA can make contribution to cancer cell hyperproliferation, invasion and metastasis. The abnormal upregulation of NEAT1, a newly described lncRNA, has been observed in many cancers and play critical roles in tumorigenesis [36-38]. Higher NEAT1 expression is positively correlated with patient age, vascular invasion, lymphatic metastasis and TNM staging [13]. More importantly, NEAT1 expression is also up-regulated in lung cancer tissues or plasma [12, 13]; increased NEAT1 expression is related to unfavorable prognosis in patients with lung cancer, thus is regarded as a diagnosis marker [12]. Herein, we validated the increased NEAT1 expression in lung adenocarcinoma specimens, as well as the correlation between higher NEAT1 expression and shorter overall survival in patients. NEAT1 overexpression also promotes lung adenocarcinoma cell proliferation and migration; thereby, investigating the mechanism of abnormal NEAT1 overexpression and rectifying the dysregulation of NEAT1 may represent a promising strategy for lung adenocarcinoma treatment.

The activation of NF- $\mathrm{kB}$, a key transcription factor which is constitutively activated in many cancers, is a crucial contributor in cancer progression $[19,20]$. NF- $\kappa B$ can be activated by miR-675, which is overexpressed in NSCLC and promotes NSCLC progression [39]. In lung cancer cells, p 65 nucleus translocation can be activated by TGF- $\beta 1$, followed by E-cadherin upregulation and increased epithelial-mesenchymal transition [40]. NF- $\mathrm{kB}$ activates the expression of proliferation-, apoptosis- and/ or migration-related genes $[14,16,26]$ after p65 nucleus translocation induced by multi factors, including TNF- $\alpha$, IL-1 and LPS [21]. Herein, we investigated whether abnormal NEAT1 overexpression is associated with NF- $\mathrm{BB}$ activation in lung adenocarcinoma. Combined with 


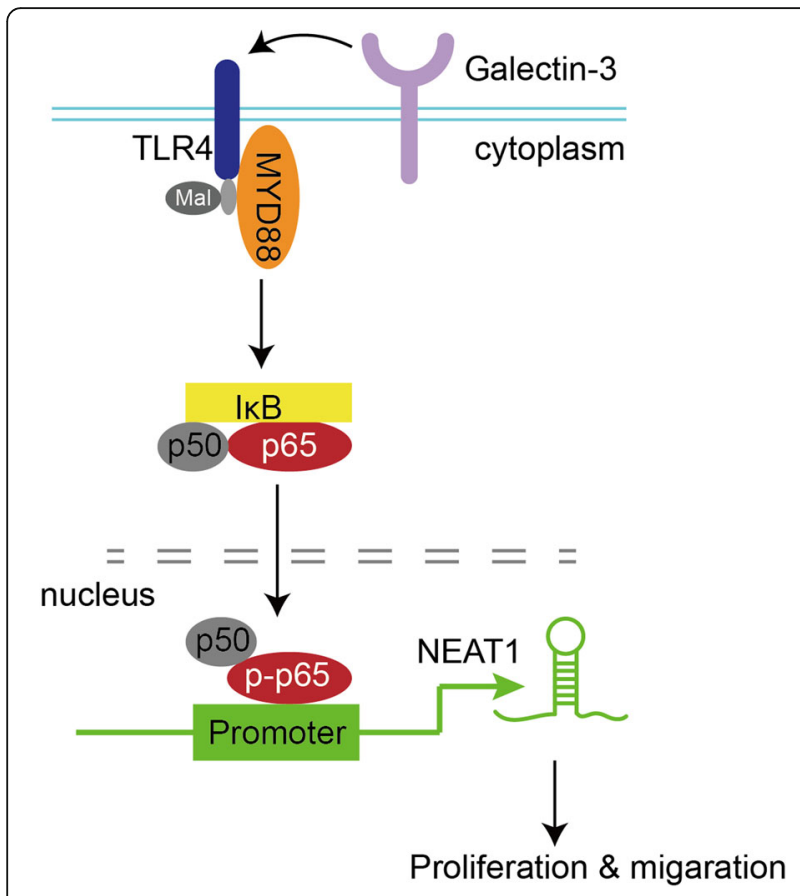

Fig. 8 Galectin-3-induced TLR4/NF-KB signaling activation contributes to lung adenocarcinoma cell proliferation and migration through activation of p65 nucleus translocation and NEAT1 expression upregulation

the results from luciferase reporter gene and ChIP assays, NF- $\mathrm{kB}$ could bind to NEAT1 promoter to activate its expression. Upon the stimulation of LPS, p-p65 protein and NEAT1 mRNA expression were both significantly increased; while these changes can be attenuated by p65 knockdown and enhance by p65 overexpression, indicating that LPS-induced NF- $\mathrm{BB}$ activation is associated with NEAT1 upregulation.

In addition to inducing p65 nucleus translocation, LPS also activates the expression of TLR4, a key factor in TLR4/NF-kB signaling pathway, another crucial pathway in the pathopoiesis of tumors [28]. LPS enhances the protein expression of TLR4 and p65 in rat pulmonary arterial smooth muscle cells [41]. Interestingly, TLR4/NF- $\mathrm{kB}$ signaling mediates diverse tumor growth $[29,30]$. In lung adenocarcinoma, LPS stimulation also caused a remarkable increase in TLR4, MyD88 and p-p65 protein expression, as well as NEAT1 mRNA expression, which could be partially reversed by CLI-095, an inhibitor of TLR4 signaling. The data indicate that TLR4/NF- $\mathrm{KB}$ signaling activation promotes NEAT1 expression through NF- $\mathrm{kB}$ binding to NEAT1 promoter. Consistent with our data, in colon cancer, NF- $\mathrm{KB}$ can be induced by LPS binding to TLR4 [42], further indicating the essential role of TLR4/NF-kB pathway in cancer development.
However, LPS-induced TLR4/NF- $\mathrm{KB}$ activation has been well studied in cancers; herein, we investigated other possible upstream factors which can activate this key signaling pathway in lung adenocarcinoma.

Galectins, a series of proteins also known as animal lectins, possess different biological activities. Galectins can participate in diverse cellular physiological activities through interaction with either cell-surface and extracellular matrix glycoproteins and glycolipids, or intracellular cytoplasmic and nuclear proteins. Galectin-3 can induce ovarian cancer cell survival and chemoresistance through activating TLR4 pathway [33]. We revealed that Galectin-3-induced TLR4 signaling activation is involved in miR-548c regulation of lung cancer cell proliferation (data not shown). Herein, we also observed that Galectin-3 overexpression remarkably induced TLR4 protein expression, as well as lung adenocarcinoma cell proliferation and migration; next, we further investigated whether Galectin-3 exerts its function through downstream NF-kB and NEAT1. Similar as LPS, Galectin-3 overexpression also caused a dramatical increase in TLR4, MyD88 and p-p65 proteins and NEAT1 mRNA expression, which could also be partially reversed by CLI-095; in addition, the promotive effects of Galectin-3 on lung adenocarcinoma cell proliferation and migration was also partially attenuated by CLI095. The data indicate that Galectin-3 induces TLR4/ NF- $\mathrm{kB}$ signaling activation, followed by NEAT1 expression upregulation, and ultimately promotes lung adenocarcinoma cell proliferation and migration. Finally, we revealed a higher expression of Galectin-3 and TLR4 in lung cancer tissues; Galectin-3, TLR4 and NEAT1 was positively correlated with each other, indicating that Galectin-3/TLR4/NF- $\mathrm{kB} / \mathrm{NEAT} 1$ path might be another contributor to the excessive cancer cell proliferation and migration of lung adenocarcinoma. Interestingly, data from online database TCGA indicated that Galectin-3 or TLR4 expression was not significantly correlated with the overall survival of patients with lung adenocarcinoma (sample size $=343$, Additional file 1: Figure S1); considering that lower NEAT1 expression was significantly correlated with longer overall survival, the significance of NEAT1 being a potential prognosis marker might be greater.

Regarding the shortcomings of the present study, the expression and function of Galectin-3 in healthy cell lines should be examined before the application of Galectin-3 to clinical use, in order to ensure the safety and efficiency. Moreover, due to the wide activation of NF- $\mathrm{B}$ in cancers, the efficiency of Galectin3/TLR4/NF-kB/NEAT1 path should be compared with NF- $\kappa B$ activation induced by other factors in vitro and in vivo. 


\section{Conclusions}

We demonstrated Galectin-3-induced TLR4/NF-кB signaling activation could contribute to lung adenocarcinoma cell proliferation and migration through p65 nucleus translocation and NEAT1 expression upregulation; Galectin-3/TLR4/NF-кB/NEAT1 path might be another contributor to the hyperproliferation and migration of lung adenocarcinoma cells.

\section{Additional file}

Additional file 1: Figure S1. Data from online database TCGA analyzing the correlation of Galectin-3 ( $A$ and $C$ ) or TLR4 expression ( $B$ and D) with the overall survival of patients with lung adenocarcinoma. (TIF $1101 \mathrm{~kb}$ )

\section{Abbreviations}

BCA: Bicinchoninic acid; ChIP: Chromatin immunoprecipitation; FE: Foldenrichment; IncRNAs: Long non-coding RNAs; LPS: Lipopolysac-charide; MTT: 3-(4,5-dimethylthiazol-2-yl)-2,5-diphenyltetrazolium bromide; NC: Negative control; ncRNAs: Non-coding RNAs; NEAT1: Nuclear enriched abundant transcript 1; NSCLC: Non-small cell lung cancer; p65RE: P65 responsive element; SD: Standard deviation; WB: Western blot

\section{Funding}

This work (experimental instruments, agents and experiment process) was supported by National Natural Science Foundation of China [81172226].

\section{Availability of data and materials}

All data generated or analyzed during this study are included in this published article. The datasets used and/or analyzed during the current study are available from the corresponding author on reasonable request.

\section{Authors' contributions}

WZ designed and performed the experiments, wrote the manuscript. XC1, $\mathrm{QH}, \mathrm{XC2}$ and YC have contributed to experimental work and data analysis. $\mathrm{LH}$ conducted the experiments and revised the manuscript. All authors have read and approved the final manuscript.

\section{Ethics approval and consent to participate}

The study was conducted in accordance with the Declaration of Helsinki, and the protocol was approved by the Ethic Committee of Xiangya Hospital, Central South University. All of the enrolled lung cancer patients signed informed consent forms.

\section{Competing interests}

The authors declare that they have no competing interests.

\section{Publisher's Note}

Springer Nature remains neutral with regard to jurisdictional claims in published maps and institutional affiliations.

Received: 20 November 2017 Accepted: 30 April 2018

Published online: 22 May 2018

\section{References}

1. Morgensztern D, Campo MJ, Dahlberg SE, Doebele RC, Garon E, Gerber DE, Goldberg SB, Hammerman PS, Heist RS, Hensing T, et al. Molecularly targeted therapies in non-small-cell lung cancer annual update 2014. Thorac Oncol. 2015;10(1 Suppl 1):S1-63.

2. Siegel RL, Miller KD, Jemal A. Cancer statistics, 2016. CA Cancer J Clin. 2016; 66(1):7-30.

3. Aberle DR, Adams AM, Berg CD, Black WC, Clapp JD, Fagerstrom RM, Gareen IF, Gatsonis C, Marcus PM, Sicks JD. Reduced lung-cancer mortality with low-dose computed tomographic screening. N Engl J Med. 2011; 365(5):395-409.
4. Djebali S, Davis CA, Merkel A, Dobin A, Lassmann T, Mortazavi A, Tanzer A Lagarde J, Lin W, Schlesinger F, et al. Landscape of transcription in human cells. Nature. 2012;489(7414):101-8.

5. Martens-Uzunova ES, Bottcher R, Croce CM, Jenster G, Visakorpi T, Calin GA. Long noncoding RNA in prostate, bladder, and kidney cancer. Eur Urol. 2014;65(6):1140-51.

6. Ponting CP, Oliver PL, Reik W. Evolution and functions of long noncoding RNAs. Cell. 2009;136(4):629-41.

7. Huang B, Liu C, Wu Q, Zhang J, Min Q, Sheng T, Wang X, Zou Y. Long non-coding RNA NEAT1 facilitates pancreatic cancer progression through negative modulation of miR-506-3p. Biochem Biophys Res Commun. 2017;482(4):828-34

8. Qian K, Liu G, Tang Z, Hu Y, Fang Y, Chen Z, Xu X. The long non-coding RNA NEAT1 interacted with miR-101 modulates breast cancer growth by targeting EZH2. Arch Biochem Biophys. 2017;615:1-9.

9. Li S, Yang J, Xia Y, Fan Q, Yang KP. LncRNA NEAT1 promotes proliferation and invasion via targeting MiR-181a-5p in non-small cell lung Cancer. Oncol Res. 2018;26(2):289-96. https://doi.org/10.3727/096504017X15009404458675. Epub 2017 Jul 25.

10. Sun C, Li S, Zhang F, Xi Y, Wang L, Bi Y, Li D. Long non-coding RNA NEAT1 promotes non-small cell lung cancer progression through regulation of miR-377-3p-E2F3 pathway. Oncotarget. 2016;7(32):51784-814.

11. He C, Jiang B, Ma J, Li Q. Aberrant NEAT1 expression is associated with clinical outcome in high grade glioma patients. APMIS 124 2016;(3):169-74.

12. Hu X, Bao J, Wang Z, Zhang Z, Gu P, Tao F, Cui D, Jiang W. The plasma IncRNA acting as fingerprint in non-small-cell lung cancer. Tumour Biol. 2016;37(3):3497-504

13. Pan $L$, Zhong TF, Tang RX, Li P, Dang YW, Huang SN, Chen G. Upregulation and clinicopathological significance of long non-coding NEAT1 RNA in NSCLC tissues. Asian Pac J Cancer Prev. 2015;16(7):2851-5.

14. Ben-Neriah Y, Karin M. Inflammation meets cancer, with NF-kappaB as the matchmaker. Nat Immunol. 2011;12(8):715-23.

15. Rayet $B$, Gelinas $C$. Aberrant rel/nfkb genes and activity in human cancer. Oncogene. 1999;18(49):6938-47.

16. Baldwin AS. Control of oncogenesis and cancer therapy resistance by the transcription factor NF-kappaB. J Clin Invest. 2001;107(3):241-6.

17. Karin M, Cao Y, Greten FR, Li ZW. NF-kappaB in cancer: from innocent bystander to major culprit. Nat Rev Cancer. 2002;2(4):301-10.

18. Yamamoto Y, Gaynor RB. Therapeutic potential of inhibition of the NFkappaB pathway in the treatment of inflammation and cancer. J Clin Invest. 2001;107(2):135-42.

19. DiDonato JA, Mercurio F, Karin M. NF-kappaB and the link between inflammation and cancer. Immunol Rev. 2012;246(1):379-400.

20. Fornier MN, Rathkopf D, Shah M, Patil S, O'Reilly E, Tse AN, Hudis C, Lefkowitz R, Kelsen DP, Schwartz GK. Phase I dose-finding study of weekly docetaxel followed by flavopiridol for patients with advanced solid tumors. Clin Cancer Res. 2007;13(19):5841-6.

21. Carbone C, Melisi D. NF-kappaB as a target for pancreatic cancer therapy. Expert Opin Ther Targets. 2012;16(Suppl 2):S1-10.

22. Thu KL, Pikor LA, Chari R, Wilson IM, Macaulay CE, English JC, Tsao MS, Gazdar AF, Lam S, Lam WL, et al. Genetic disruption of KEAP1/CUL3 E3 ubiquitin ligase complex components is a key mechanism of NF-kappaB pathway activation in lung cancer. J Thorac Oncol. 2011;6(9):1521-9.

23. Yi C, Wang Y, Zhang C, Xuan Y, Zhao S, Liu T, Li W, Liao Y, Feng X, Hao J, et al. Cleavage and polyadenylation specific factor 4 targets NF-kappaB/ cyclooxygenase-2 signaling to promote lung cancer growth and progression. Cancer Lett. 2016:381(1):1-13.

24. Bai F, Zhou H, Fu Z, Xie J, Hu Y, Nie S. NF-kappaB-induced WIP1 expression promotes colorectal cancer cell proliferation through mTOR signaling. Biomed Pharmacother. 2018;99:402-10.

25. Chung LY, Tang SJ, Sun GH, Chou TY, Yeh TS, Yu SL, Sun KH. Galectin-1 promotes lung cancer progression and chemoresistance by upregulating p38 MAPK, ERK, and cyclooxygenase-2. Clin Cancer Res. 2012;18(15):4037-47.

26. Joyce D, Albanese C, Steer J, Fu M, Bouzahzah B, Pestell RG. NF-kappaB and cell-cycle regulation: the cyclin connection. Cytokine Growth Factor Rev. 2001;12(1):73-90.

27. Khan A, Fornes O, Stigliani A, Gheorghe M, Castro-Mondragon JA, van der Lee R, Bessy A, Cheneby J, Kulkarni SR, Tan G, et al. JASPAR 2018: update of the open-access database of transcription factor binding profiles and its web framework. Nucleic Acids Res. 2018;46(D1):D260-6. 
28. Kelly MG, Alvero AB, Chen R, Silasi DA, Abrahams VM, Chan S, Visintin I, Rutherford T, Mor G. TLR-4 signaling promotes tumor growth and paclitaxel chemoresistance in ovarian cancer. Cancer Res. 2006;66(7):3859-68.

29. Zhu J, Luo J, Li Y, Jia M, Wang Y, Huang Y, Ke S. HMGB1 induces human non-small cell lung cancer cell motility by activating integrin alphavbeta3/ FAK through TLR4/NF-kappaB signaling pathway. Biochem Biophys Res Commun. 2016;480(4):522-7.

30. Huang HY, Zhang ZJ, Cao CB, Wang N, Liu FF, Peng JQ, Ren XJ, Qian J. The TLR4/NF-kappaB signaling pathway mediates the growth of colon cancer. Eur Rev Med Pharmacol Sci. 2014;18(24):3834-43.

31. Arad U, Madar-Balakirski N, Angel-Korman A, Amir S, Tzadok S, Segal O, Menachem A, Gold A, Elkayam O, Caspi D. Galectin-3 is a sensor-regulator of toll-like receptor pathways in synovial fibroblasts. Cytokine. 2015;73(1):30-5.

32. Burguillos MA, Svensson M, Schulte T, Boza-Serrano A, Garcia-Quintanilla A, Kavanagh E, Santiago M, Viceconte N, Oliva-Martin MJ, Osman AM, et al. Microglia-secreted Galectin-3 acts as a toll-like receptor 4 ligand and contributes to microglial activation. Cell Rep. 2015. https://doi.org/10.1016/j. celrep.2015.02.012. [Epub ahead of print].

33. Cai G, Ma X, Chen B, Huang Y, Liu S, Yang H, Zou W. Galectin-3 induces ovarian cancer cell survival and chemoresistance via TLR4 signaling activation. Tumour Biol. 2016;37(9):11883-91.

34. Yoshimura A, Gemma A, Hosoya Y, Komaki E, Hosomi Y, Okano T, Takenaka K, Matuda K, Seike M, Uematsu K, et al. Increased expression of the LGALS3 (galectin 3) gene in human non-small-cell lung cancer. Genes Chromosomes Cancer. 2003;37(2):159-64.

35. Liu M, Du B, Li C, Zhao Y, Meng Q, Cai L. Expression and related factors of Galectin3 in non-small cell lung cancer. Zhongguo Fei Ai Za Zhi. 2013;16(8):417-21.

36. Yu X, Li Z, Zheng H, Chan MT, Wu WK. NEAT1: a novel cancer-related long non-coding RNA. Cell Prolif. 2017;50(2). https://doi.org/10.1111/cpr.12329. Epub 2017 Jan 19

37. Wang Z, Zou Q, Song M, Chen J. NEAT1 promotes cell proliferation and invasion in hepatocellular carcinoma by negative regulating miR-613 expression. Biomed Pharmacother. 2017;94:612-18.

38. Xiong W, Huang C, Deng H, Jian C, Zen C, Ye K, Zhong Z, Zhao X, Zhu L. Oncogenic non-coding RNA NEAT1 promotes the prostate cancer cell growth through the SRC3/IGF1R/AKT pathway. Int. J. Biochem. Cell Biol. 2018;94:125-32.

39. Feng Y, Yang C, Hu D, Wang X, Liu X. miR-675 promotes disease progression of non-small cell lung cancer via activating NF-kappaB signaling pathway. Cell Mol Biol (Noisy-le-grand). 2017;63(5):7-10

40. Feng H, Lu JJ, Wang Y, Pei L, Chen X. Osthole inhibited TGF beta-induced epithelial-mesenchymal transition (EMT) by suppressing NF-kappaB mediated snail activation in lung cancer A549 cells. Cell Adh Migr. 2017;11(5-6):464-75. https://doi.org/10.1080/19336918.2016.1259058. Epub 2017 Feb 2.

41. Wang P, Han X, Mo B, Huang G, Wang C. LPS enhances TLR4 expression and IFNgamma production via the TLR4/RAK/NFkappaB signaling pathway in rat pulmonary arterial smooth muscle cells. Mol Med Rep. 2017;16(3):3111-6.

42. Liu L, Li YH, Niu YB, Sun Y, Guo ZJ, Li Q, Li C, Feng J, Cao SS, Mei QB. An apple oligogalactan prevents against inflammation and carcinogenesis by targeting LPS/TLR4/NF-kappaB pathway in a mouse model of colitisassociated colon cancer. Carcinogenesis. 2010;31(10):1822-32.

\section{Ready to submit your research? Choose BMC and benefit from:}

- fast, convenient online submission

- thorough peer review by experienced researchers in your field

- rapid publication on acceptance

- support for research data, including large and complex data types

- gold Open Access which fosters wider collaboration and increased citations

- maximum visibility for your research: over $100 \mathrm{M}$ website views per year

At BMC, research is always in progress.

Learn more biomedcentral.com/submissions 